\title{
HIỆN TƯợNG LÚN MỐC Độ CAO QUỐC GIA TẠI KHU VỤ̉C PHÍA NAM VÀ GIẢI PHÁP KHẮC PHỤC
}

\author{
TS. VŨ XUÂN CƯỜNG ${ }^{(1)}$, ThS. VŨ VĂN THÁl(2), KS. TRẦ ĐìNH ẤU(3) \\ ${ }^{(1)}$ ĐH Tài nguyên và Môi trường TP. Hồ Chí Minh \\ ${ }^{(2)}$ Chi cục Đo đạc và Bản đồ phía Nam \\ ${ }^{(3)}$ Hội Trắc địa, Bản đồ TP. Hồ Chí Minh
}

\section{Tóm tắt:}

Những năm gần đây, hiện tượng các công trình bị lún, sụt, bị nghiêng, bị hư hại tại các đô thị lớn xảy ra ngày càng nhiều. Điều đáng lưu tâm là hiện tượng lún cục bộ trên những nền đất yếu không chỉ liên quan đến các công trình xây dựng dân dụng và hệ thống cơ sở hạ tầng mà còn ảnh hưởng trực tiếp đến các công trình đo đạc bản đồ, đặc biệt là các mốc độ cao quốc gia tại khu vực phía Nam. Hiện tượng này đang trở thành thách thức thực sự cho ngành đo đạc bản đồ trước yêu cầu cung cấp số liệu gốc chính xác cho kịch bản biến đổi khí hậu và cung cấp số liệu độ cao cho các mục tiêu kinh tế - xã hội nói chung. Bài báo này nhằm mục tiêu khẳng định mức độ nghiêm trọng của hiện tượng lún mốc độ cao quốc gia tại khu vực phía Nam và đề xuất một số giải pháp cần thiết để khắc phục.

\section{1. Đặt vấn đề}

Từ năm 1976 đến năm 1987, Cục Đo đạc và Bản đồ Nhà nước đã tiến hành xây dựng hệ thống mốc, đo tuyến độ cao Vĩnh Linh Hà Tiên nhằm thống nhất Lưới độ cao Quốc gia và đo lặp các đường độ cao hạng I, II miền Bắc. Từ năm 2001 tới năm 2008, Cục Đo đạc và Bản đồ Việt Nam đã tiến hành đo lặp Lưới độ cao Quốc gia trên cả nước. Lưới độ cao Quốc gia hạng I, hạng II, là cơ sở để xây dựng hệ thống thủy lợi Đồng bằng Sông Cửu Long góp phần cải tạo Đồng Tháp Mười thành vựa lúa của cả nước, làm cơ sở thành lập hệ thống bản đồ địa hình các tỷ lệ phục vụ đắc lực cho việc phát triển kinh tế xã hội và phòng chống lũ lụt các tỉnh miền Nam.

Hệ thống mốc độ cao Quốc gia được xây dựng theo "Quy phạm xây dựng lưới độ cao nhà nước hạng 1,2,3 và 4" với các loại mốc cơ bản, mốc thường trên vùng đất chắc, vùng đất yếu, vỉa đá ngầm. Do các điều kiện hạn chế kinh tế, kỹ thuật, các mốc độ cao xây dựng trên vùng đất yếu được quy định xử lý nền móng bằng cọc cừ tràm. Trong quá trình sử dụng các mốc độ cao Quốc gia hạng I, hạng II, và hạng III tại một số khu vực xuất hiện hiện tượng lún cục bộ trên nền đất yếu dẫn tới thay đổi giá trị độ cao của mốc.

Trong các năm gần đây các số liệu độ cao Quốc gia cấp cho các đơn vị sử dụng làm số liệu gốc thi công các công tình xây dựng, thủy lợi, giao thông, đo đạc bản đồ tại miền Nam thường xuyên nhận được các phản hồi tình trạng sụt lún tại các mốc độ cao dẫn tới sai số do dữ liệu gốc vượt hạn sai cho phép. Đặc biệt tại dự án Chính phủ "Thủy lợi phòng chống ngập lụt Thành phố Hồ Chí Minh", năm 2011 qua đo kiểm tra có 4/11 mốc độ cao hạng I bị lún cục bộ, dẫn tới sai số độ cao đo kiểm tra chênh so với độ cao gốc được cấp từ $0.2 \mathrm{~m}$ tới $0.6 \mathrm{~m}$.

Để đảm bảo số liệu độ cao một cách tin cậy tại khu vực miền $\mathrm{Nam}$ và cung cấp số liệu gốc chính xác cho kịch bản biến đổi khí hậu, cần tiến hành xây dựng cải tạo hệ thống mốc, đồng thời xác định các vị trí mốc ổn định để tiến hành đo nối, khôi phục độ chính xác cho Lưới độ cao Quốc gia phục 
vụ kịp thời nhu cầu phát triển kinh tế xã hội, quốc phòng an ninh. Trong khuôn khổ bài báo này, nhóm tác giả trình bày một số kết quả nghiên cứu thuộc đề tài "Nghiên cứu cơ sở khoa học và thực tiễn việc chọn điểm, chôn mốc độ cao Quốc gia tại những vị trî có nền đất yếu làm cơ sở xây dựng, cải tạo hệ thống mốc, khôi phục độ chính xác Lưới độ cao miền Nam" với nội dung chính là nghiên cứu, đánh giá tình trạng để đưa ra giải pháp cải tạo hệ thống mốc, khôi phục độ chính xác Lưới độ cao miền Nam.

\section{Giải quyết vấn đề}

2.1. Đánh giá tình trạng hệ thống mốc độ cao quốc gia tại khu vực nghiên cứu

Tại khu vực phía Nam, qua thực tế khai thác, sử dụng số liệu cao độ quốc gia cho thấy có nhiều mốc độ cao bị ảnh hưởng, tác động bởi các yếu tố tự nhiên (ngập lụt, nền đất yếu) và hoạt động của con người (khai thác nước ngầm, xây dựng nhiều công trình dân dụng trên đất gần khu vực có mốc ...).

Tại công trình nghiên cứu này, nhóm tác giả cũng đã nghiên cứu kinh nghiệm xây dựng mốc độ cao của một số nước trên thế giới, những giải pháp xây dựng mốc độ cao quốc gia trên nền đất yếu, những vùng đất có điều kiện tương đồng với điều kiện của Việt Nam. Qua nghiên cứu kinh nghiệm các nước cho thấy, việc xây dựng mốc độ cao được phân tích khá kỹ lưỡng, quá trình chôn mốc dựa trên việc xác định tính chất, các yếu tố ảnh hưởng khác nhau. Tại Liên bang Nga, việc chôn mốc được xác định theo các phân vùng lãnh thổ, các mốc độ cao cũng sẽ có rất nhiều chủng loại với kích thước và hình dạng khác nhau tương ứng với các nền đất khác nhau. Tại các nước Châu Mỹ, tính ổn định của mốc trắc địa nói chung và độ cao nói riêng được đặc biệt quan tâm. Hai yếu tố quan trọng hàng đầu ảnh hưởng đến mức độ ổn định của mốc được xác định là thổ nhưỡng và địa chất. Tại các nước Đông Nam Á, gần với điều kiện của Việt Nam như Malaysia mốc độ cao được bố trí theo lưới, các tuyến chạy theo các trục đường giao thông. Malaysia có 2 loại cấp hạng mốc độ cao: loại độ cao chuẩn và độ cao thông thường. Mốc độ cao chuẩn được đặt cách nhau khoảng $40 \mathrm{~km}$, các mốc độ cao thông thường cách nhau khoảng $1 \mathrm{~km}$ (trong khu vực thành thị là 0.5

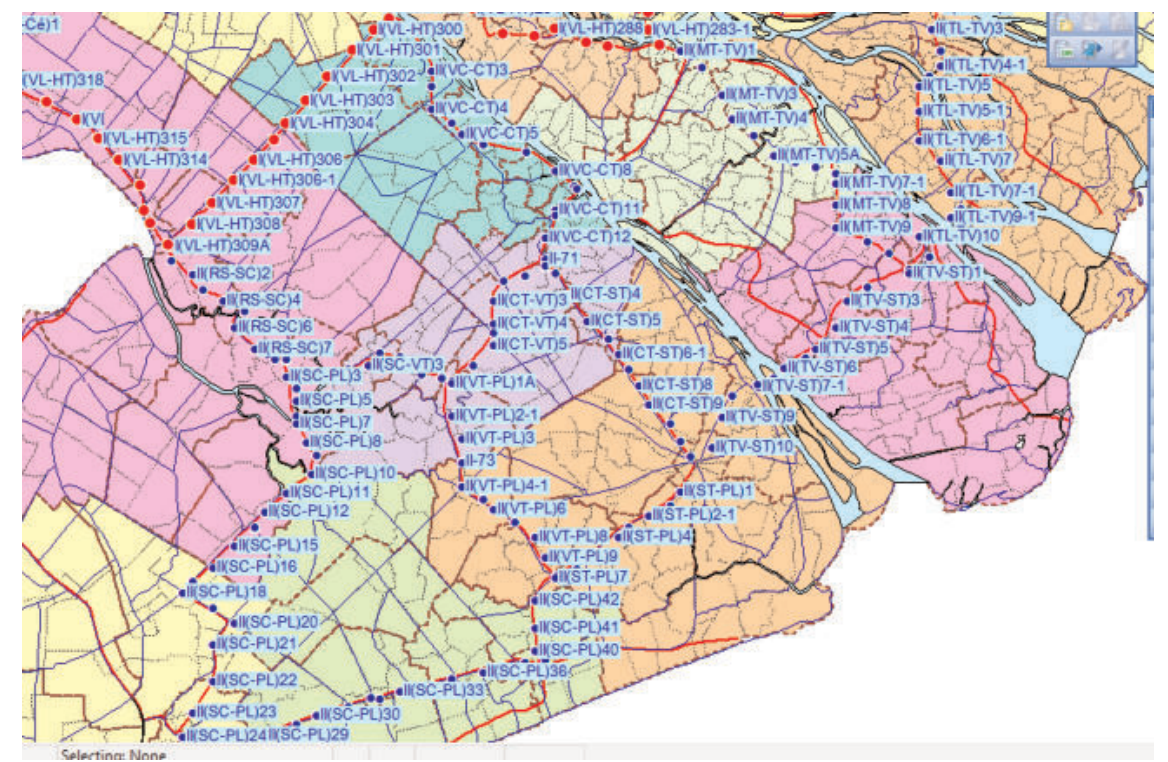

Hình 1: Sơ đồ các tuyến thủy chuẩn hạng I, II 


\section{Nghiên cúu - Úng dụng}

Bảng 1: Kết quả đo kiểm tra một số mốc độ cao hạng I và II quốc gia

\begin{tabular}{|c|c|c|c|c|c|}
\hline Tên điểm & $\begin{array}{c}\text { Khoảng cách } \\
(\mathrm{km})\end{array}$ & $\begin{array}{c}\text { Độ cao đã câp } \\
(\mathrm{m})\end{array}$ & Chênh cao $(\mathrm{m})$ & $\begin{array}{c}\text { Chênh cao } \\
\text { kiểm tra }(\mathrm{m})\end{array}$ & Độ lệch $(\mathrm{m})$ \\
\hline II(TX-TL)6 & & 1.319 & & & \\
\hline & 5 & & 0.200 & 0.192 & 0.008 \\
\hline II(TX-TL)4 & & 1.519 & & & \\
\hline $\mathrm{I}(\mathrm{VL}-\mathrm{HT}) 259$ & & 7.129 & & & \\
\hline & 10 & & 6.318 & 6.452 & 0.183 \\
\hline $\mathrm{I}(\mathrm{VL}-\mathrm{HT}) 257$ & & 0.811 & & & \\
\hline $\mathrm{I}(\mathrm{VL}-\mathrm{HT}) 262 \mathrm{~A}$ & & 0.940 & & & \\
\hline & 4.9 & & 0.632 & 1.104 & -0.472 \\
\hline $\mathrm{I}(\mathrm{VL}-\mathrm{HT}) 261$ & & 1.572 & & & \\
\hline
\end{tabular}

Bảng 2: Kết quả đo kiểm tra một số mốc độ cao hạng III

\begin{tabular}{|c|c|c|c|c|}
\hline Tên điểm & Độ cao gốc $(\mathrm{m})$ & Chênh cao $(\mathrm{m})$ & $\begin{array}{c}\text { Chênh cao } \\
\text { kiểm tra }(\mathrm{m})\end{array}$ & Độ lệch $(\mathrm{m})$ \\
\hline Q01-027 & 1.646 & & & \\
\hline & & 0.345 & 0.354 & -0.009 \\
\hline Q01-064 & 1.991 & & & \\
\hline & & -0.023 & -0.018 & -0.005 \\
\hline Q01-019 & 1.968 & & & \\
\hline Q01-020 & & 1.044 & 1.055 & -0.011 \\
\hline & 3.012 & & & \\
\hline Q01-021 & 1.919 & -1.093 & -1.100 & 0.007 \\
\hline & & & & \\
\hline QBT1-039 & 2.630 & & 0.711 & \\
\hline & & -1.503 & -1.128 & -0.375 \\
\hline QBT1-035 & 1.127 & & & \\
\hline & & 0.161 & -0.352 & 0.513 \\
\hline QBT1-042 & 1.288 & & & \\
\hline
\end{tabular}
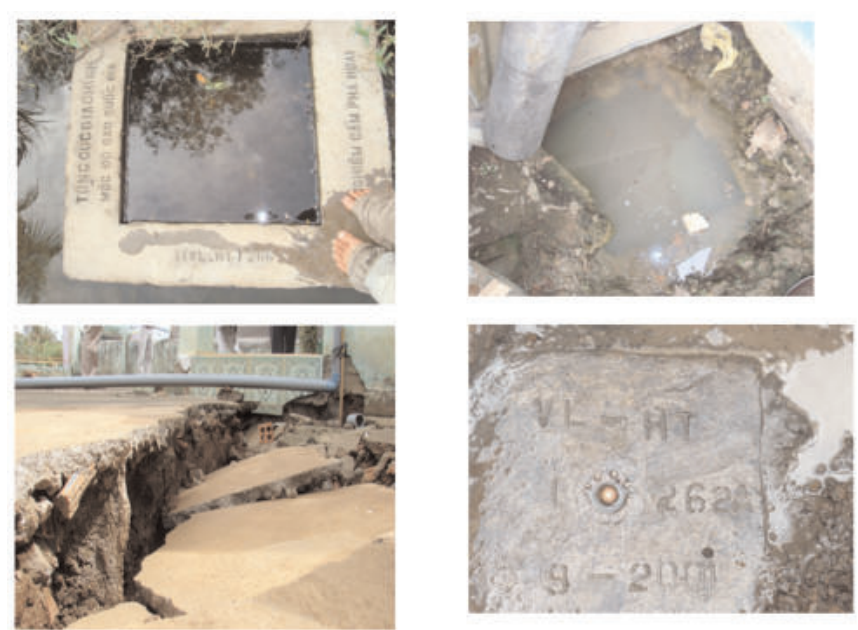

Hình 2: Hình ảnh một số mốc độ cao bị sụt, lún 
km) được bố trí giữa các mốc độ cao chuẩn. Khu vực đất có cấu trúc địa chất yếu người ta sử dụng loại mốc bằng ống thép để nén xuống lòng đất mà không cần phải đào.

Tại Việt Nam, cho đến nay trong "Quy chuẩn kỹ thuật quốc gia về xây dựng lưới độ cao" việc xây dựng các mốc độ cao các cấp hạng chưa được xem xét đến các yếu tố địa chất, cơ lý đất, khí tượng thủy văn, tác động của con người (các hoạt động giao thông, xây dựng, khai thác nước ngầm...). Đến nay chưa có một khảo sát địa chất nào về sự lún của các mốc độ cao tại khu vực xây dựng mốc ở các vùng đất yếu để đưa ra các biện pháp khắc phục. "Quy chuẩn kỹ thuật quốc gia về xây dựng lưới độ cao" chỉ đưa ra điều kiện chung chung cho các vùng đất yếu là xử lý nền móng bằng cọc cừ tràm khi chôn mốc (hình 3). Mỗi một mốc được đóng 9 cọc cừ tràm dài khoảng $3-4 \mathrm{~m}$ xuống nền đất yếu sau đó tạo 1 lớp bê tông và chôn mốc xuống, như vậy qua thời gian các cọc tràm này bị ăn mòn, bị mục nên không thể giữ nổi mốc đối với nền đất yếu có cấu trúc địa tầng chung cho khu vực Đồng bằng sông Cửu Long (hình 4). Do vậy, quy định này chưa sát thực tế địa chất của vùng đất yếu (đặc biệt là Đồng bằng sông Cửu Long) và đó là nguyên nhân chính dẫn đến tình trạng sụt lún mốc nói trên.

Cấp độ lún đối với các mốc độ cao do cấu trúc địa tầng địa chất vùng đất yếu có thể lên tới từ vài decimet đến mét, do ảnh hưởng của yếu tố nhân tạo như quá gần các đường giao thông lớn như quốc lộ $1 \mathrm{~A}$ khoảng vài decimet (ở đây chưa đề cập tới việc mốc bị mất do quá trình đô thị hóa) và do ảnh hưởng của việc khai thác nước ngầm toàn khu vực khoảng vài milimet đến centimet. Do vậy nguyên nhân chính dẫn đến sự lún của mốc độ cao là do quy cách mốc chưa phù hợp, chưa đúng đối với cấu trúc địa tầng địa chất và vị trí đặt các mốc chưa phù hợp với thực tế.

Như vậy có thể xác định các nguyên nhân xảy ra lún mốc độ cao tại những vùng đất yếu ở nước ta gồm những nguyên nhân sau:

- Do thời gian và và giới hạn phương tiện kỹ thuật: Nhiều mốc được xây dựng cách đây trên 30 năm với những xử lý kỹ thuật chưa đảm bảo tại những khu vực nền đất yếu.

- Do ảnh hưởng các yếu tố: địa chất, cơ lý đất, khí hậu, thủy văn, nhân tạo. Những khu vực có nền đất yếu là những nờ mà

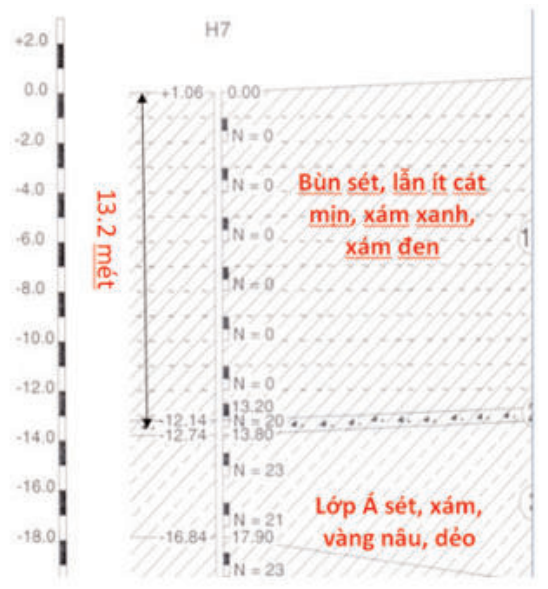

Hình 4: Cấu trúc địa tầng chung của khu vực đồng bằng sông Cửu Long
Hình 3: Chống lún cho mốc độ cao theo Quy chuẩn kỹ thuật về xây dựng lưới độ cao

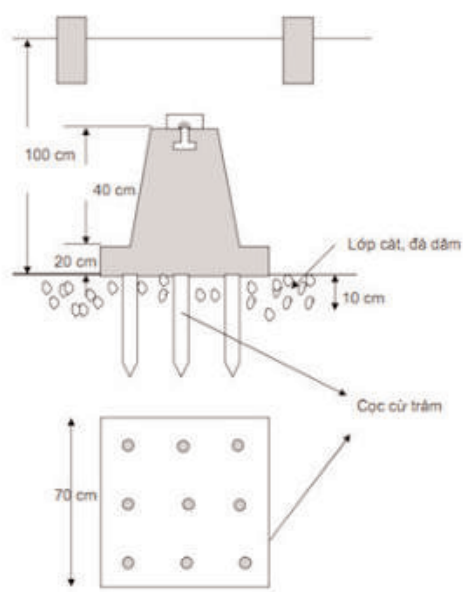

chuan kỹ thuạt ve xay dụng luơi đọ cao 
qua đo kiểm tra có mức độ lún rất lớn. Những mốc độ cao bên cạnh tuyến giao thông có lưu lượng lưu thông lớn cũng bị ảnh hưởng nhiều. Ngoài ra, việc xây dựng các công trình dân dụng với mật độ cao tại các đô thị cũng làm cho bề mặt đất bị lún. Việc khai thác nước ngầm một cách tràn lan cũng là lý do làm cho mặt đất bị lún xuống kéo theo việc lún của những mốc độ cao quốc gia.

- Quan trọng nhất: Quy trình chọn điểm, chôn mốc độ cao Quốc gia (đặc biệt tại những vị trí có nền đất yếu) còn hạn chể, thiếu những cơ sở khoa học cần thiết.

\subsection{Các giải pháp}

\section{a. Giải pháp tổng quát}

Để khắc phục sự sụt lún của các mốc độ cao như đã phân tích trên giải pháp tổng hợp và bao quát nhất là dựa trên bản đồ tổng thể địa chất phân tích, đánh giá và chia ra các cấp độ có thể gây lún khi chôn mốc độ cao theo từng vùng (vùng địa chất), từ đó đưa ra cấu trúc các loại mốc độ cao cho phù hợp với từng vùng cấu trúc địa chất đó. Chúng ta thấy rằng hiện nay loại mốc độ cao như hình 3 là không phù hợp với vùng đất yếu do đó nên kiến nghị với cơ quan thẩm quyền là không nên sử dụng tiếp tục. Thay vào đó là nên sử dụng loại mốc khoan (ống thép) sâu đến lớp Á sét xám (hình 5) để đảm bảo mốc được ổn định. Trên địa bàn TP. Hồ Chí Minh đã có 3 mốc độ cao được khoan sâu xuống $70 \mathrm{~m}$ và dùng ống thép nhồi bê tông do Trung tâm chống ngập TP thực hiện, tất nhiên kinh phí xây dựng các mốc này rất lớn.

\section{b. Giải pháp chuyên đề}

Vị trí xây dựng các mốc độ cao không nên quá gần với các đường giao thông có mật độ và phương tiện trọng tải lớn lưu thông (thực tế hiện nay có mốc chỉ cách vài mét nên ảnh hưởng rất lớn đến sự ổn định của mốc). Khoảng cách từ đường giao thông đến mốc phải càng xa càng tốt (tối thiểu từ 150 mét).

Quá trình phát triển đô thị gây sự mất ổn định của mốc độ cao nhưng cũng có thuận lợi khi đã được ổn định. Các mốc độ cao có thể tận dụng các nhà cao tầng có móng sâu đến địa tầng vững chắc để đặt các mốc gắn sau khi đã ổn định lún. Đối với các mốc này thì yếu tố lún do địa chất không còn ảnh hưởng, có thể ảnh hưởng ít do khai thác nước ngầm ở tầng sâu hơn.
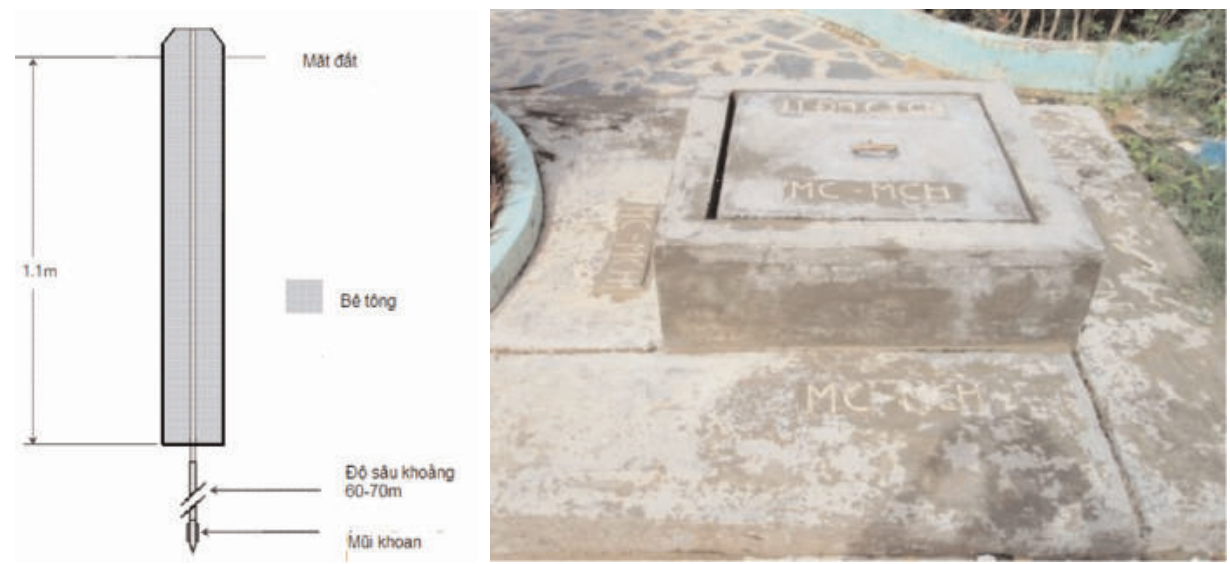

Hình 5: Thiết kế và thực tế mốc độ cao xây dựng bằng phương pháp ống khoan 
Theo "Quy phạm xây dựng lưới độ cao nhà nước hạng 1,2,3 và 4 " các đường của lưới độ cao được thiết kế đi theo các tuyến giao thông để dễ đo ngắm và vận chuyển, do vậy các mốc độ cao cơ bản hầu như phân bố không đều theo lãnh thổ, chủ yếu mật độ hạng I Nhà nước theo tuyến Vĩnh Linh - Hà Tiên (khoảng cách 5-10 km 1 điểm), nhiều tỉnh thành trong khu vực không có điểm độ cao cơ bản Nhà nước hạng I. Để phục vụ cho công tác theo dõi quá trình biến đổi khí hậu và mực nước dâng phải chăng chúng ta nên thay đổi tư duy bố trí các điểm độ cao cơ bản theo khu vực từng tỉnh thành. Trong khu vực mỗi tỉnh chỉ cần xây dựng khoảng 5-10 điểm độ cao có mốc kiên cố và sâu xuống đến địa tầng ổn định để có thể sử dụng được hàng trăm năm (có thể gọi là "mốc vĩnh cửu", hình 6) phục vụ cho công tác xây dựng các công trình có độ cao trong tầm kiểm soát và để theo dõi quá trình biến đổi khí hậu với mực nước biển dâng lâu dài.

\section{Kết luận}

Việc nghiên cứu cơ sở khoa học để xây dựng, cải tạo, khôi phục độ chính xác, hoàn thiện và hiện đại hóa hệ thống độ cao quốc gia là yêu cầu cấp thiết và cấp bách hiện nay. Hệ thống mốc độ cao với số liệu ổn định, tin cậy sẽ là cơ sở cho việc xây dựng các công trình hạ tầng giao thông, thủy lợi phòng chống ngập lụt, thoát nước....Ngoài ra, còn đặc biệt có vai trò trong chương trình quốc gia ứng phó với biến đổi khí hậu và phục vụ cho các mục tiêu phát triển kinh tế - xã hội, an ninh quốc phòng....

\section{Tài liệu tham khảo}

[1]. Quy chuẩn kỹ thuật Quốc gia về Xây dựng lưới độ cao QCVN 11:2008/BTNMT do Bộ Tài nguyên và Môi trường ban hành theo Quyết định số 11 /2008/QĐ-BTNMT ngày 18 tháng 12 năm 2008.

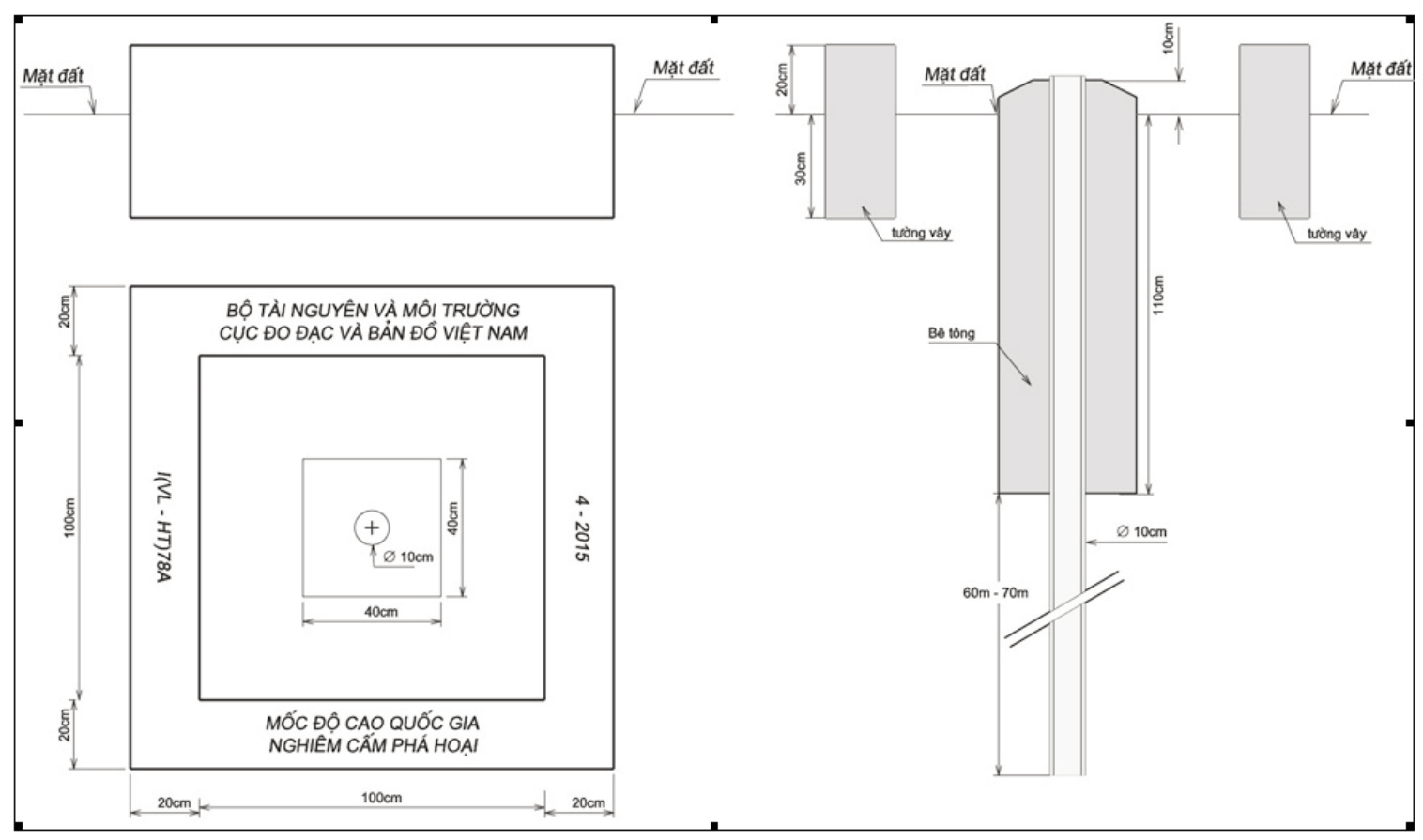

Hình 6: Thiết kế chi tiết mốc "vĩnh cửu" trên nền đất yếu 
[2]. Quy phạm xây dựng lưới độ cao nhà nước hạng 1, 2, 3 và 4" do Cục trưởng Cục Đo đạc và Bản đồ Nhà nước ban hành theo quyết định số 112/KT ngày 15 tháng 5 năm 1989.

[3]. Tô Văn Lận, Giáo trình xử lý nền móng công trình trên nền đất yếu, $Đ H$ Kiến trúc TP.HCM, TP.HCM - 2010.

[4]. Lê Xuân Mai, Đỗ Hưu Đạo, Cơ học đất, NXB Xây dựng, Hà Nội - 2005.

[5]. Bùi Anh Định, Nguyễn Sỹ Ngọc, Nền và Móng công trình cầu đường, NXB Xây dựng, Hà Nội - 2005.

[6]. Lê Anh Hoàng, Nền và Móng, NXB Xây dựng, Hà Nội - 2004.

[7]. Laréal, Nguyễn Thành Long, Lê Bá Lương, Nguyễn Quang Chiêu, Vũ Đức,
Công trình trên đất yếu trong điều kiện Việt Nam, HCMUT, TP.HCM - 1997.

[8]. Tiêu chuẩn ngành "Quy trình khảo sát thiết kế nền đường ôtô đắp trên đất yếu - 22TCN 262 - 2000" Ban hành theo Quyết định số 1398/QĐ - BGTVT ngày 1/6/2000 của Bộ trưởng Bộ GTVT.

[9]. Dự án "Hoàn thiện mạng lưới độ cao nhà nước hạng 1,2 khu vực miền Nam" được Tổng cục Địa chính phê duyệt tại Quyết định 440/QĐ-TCĐC ngày 22/11/2001;

[10]. Geodetic Bench Marks, NOAA Manual NOS NGS 1, 1978.

[11]. Abd Majid and et al., Current and Future Geodetic Activities In Malaysia, GNSS Forum, 17-18 May 2002, Hong Kong. $\mathrm{O}$

\section{Summary}

\section{The subsidence of height national benchmark in Southern area and proposed solutions}

Dr. Vu Xuan Cuong, Hochiminh City University of Natural Resource and Environment

MSc. Vu Van Thai, The Southern Sub-Department of Survey and Mapping

Eng. Tran Dinh Au, Hochiminh City Association of Geodesy and Cartography

In recent last years, the phenomenon of sinking, subsidence of building project becomes seriously in the developing urban area. This phenomenon not only impacts on the building project and utilities system but on National geodetic base, especially on the height benchmarks located on soft soil (weak) ground in Southern area. It becomes a big challenge for geodetic department in providing the accurate elevation of national benchmarks for building the climate change scenario and other industry branches. This article aims to prove the seriousness of the subsidence of National height benchmarks in Southern area and provide some solutions to avoid it. $\mathrm{O}$

Ngày nhận bài: 12/01/2015. 